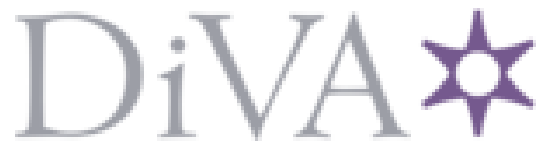

http://www.diva-portal.org

\title{
Postprint
}

This is the accepted version of a paper presented at Creativity \& Cognition.

Citation for the original published paper:

Back, J., Johansson, K., Wireband, J. (2021)

Value Driven Design for Playful Technology Enhanced Installations in Public Settings

In: Creativity and Cognition Association for Computing Machinery

$\mathrm{C} \& \mathrm{C}$ '21

https://doi.org/10.1145/3450741.3466778

N.B. When citing this work, cite the original published paper.

Permanent link to this version:

http://urn.kb.se/resolve?urn=urn:nbn:se:uu:diva-465163 


\section{Value Driven Design for Playful Technology Enhanced Installations in Public Settings}

\author{
Jon Back \\ Uppsala University \\ Uppsala, Sweden \\ jon.back@im.uu.se
}

\author{
Karin Johansson \\ Ecorado \\ Linköping, Sweden \\ karin.faktasifull@gmail.com
}

\author{
Joacim Wirebrand \\ Drakryggen \\ Linköping, Sweden \\ joacim.wirebrand@gmail.com
}

\begin{abstract}
Art and installations in public settings are often created on commission from a municipality or similar public sector. Within the public sector there are many values that the community strives to enhance. Values related to democracy, inclusion, and aesthetics are but a few. When designing for public environments, the design process might be affected by the need to strive for those values in addition to, or even rather than, the more common considerations focused on user experience or commercial aspects.
\end{abstract}

In this pictorial we present how identified core values influenced a design process aimed at designing innovative IoT-enhanced playground installations in a public setting. Inspired by annotated portfolios, we explicate how these core values influenced the final design.

Publication rights licensed to ACM. ACM acknowledges that this contribution was authored or co-authored by an employee, contractor or affiliate of a national government. As such, the Government

retains a nonexclusive, royalty-free right to publish or reproduce this article, or to allow others to do so, for Government purposes only.

C\&C '21, June 22-23, 2021, Virtual Event, Italy (C) 2021 Copyright is held by the owner/author(s). Publication rights licensed to ACM.

ACM ISBN 978-1-4503-8376-9/21/06 ..\$15.00

https://doi.org/10.1145/3450741.3466778

\section{Author Keywords}

Value driven design; playful technology; playful internet of things; outdoor play; playing out; public settings;

public sector; playground design; democracy; inclusion.

\section{CSS Concepts}

- Human-centered computing $\sim$ Human computer interaction (HCI) Interaction devices • Applied computing $\sim$ Arts and humanities $\sim$ Media arts

\section{SOCIETAL VALUES}

This pictorial presents design choices for Internet of Things-enhanced playground installations. Design choices were not primarily made for commercial reasons, and the main goal of the project was, even though it developed a real product, not to make that a sellable product. Instead the design aimed to incorporate and investigate certain values. Working towards the public sector, and working in governmentally funded projects and in research projects, this type of value-based design processes, based on societal values, often occurs. To work value based affects the design process, as well as the outcome. In the design process for this project the values were always in focus. They were identified at an early stage, and the design group aligned, as far as practically possible, all choices towards these values.

This pictorial is not intended to be a thorough study on how to identify values, neither is it a complete guide on how to incorporate societal values in a design process. This should rather be read as an inspirational case study, a design-oriented paper, or maybe even a manifesto, pointing to the importance of considering how societal values can and should be integrated into design choices. It takes its stance in one case, and is a presentation of concrete manifestations of societal values in an actual design.

\section{PREVIOUS APPROACHES TO DESIGN AND VALUE}

Value is a complicated concept, and we may not all even agree on what it means. There are many different approaches to working with values and design.

Among these can be mentioned value sensitive design, in which values are approach through three main angles: conceptual, empirical, and technical [13]. In this approach, a formative design framework is constructed where theoretical constructs are translated through several levels into toolkits, methods and heuristics to help guide the design process [17].

While value sensitive design have a strong focus on turning theory into practical support for design, a more practice oriented approach can be found in Schön [23], where active reflection in action is suggested as one of the forms of knowledge creation in design. By explicitly guiding this reflection, we can put a focus on values in the design process, while following a format that creators also outside of academia are comfortable with.

In this work, we used a similar approach to value sensitive design in turning theoretical values into practical design 
considerations. However, we have differing understandings of the meaning of the word 'value'. While value sensitive design mainly is "concerned with what people consider important in their lives, with a focus on ethics and morality" [12], for us this results in an approach focused on protecting people's rights/values. In this work 'values' should rather be read as explicating organisational and personal beliefs/values to incorporate these beliefs in the design process.

While the translation of theory into actionable items in this work is similar to value sensitive design, and reflection in action was used to make sense of our prototypes, the approach to 'values' are rather inspired by Flanagan et.al. [11], where the act of value design is separated from a traditional passive approach where designers not explicitly consider their assumptions, and risk imbuing unspoken ideals into their design. In contrasting this with deliberately embodying values into design, this latter way becomes a form of political or moral activism, where designer values are communicated to the end user.

\section{SOCIETAL VALUES IN THE DESIGN PROCESS}

More abstract long-term project DESIGN PROCESS

values, sustainable development gols such as democratic work, thus abstract that they are goals and similar can a value documg lost in the design pred in the day to day inspirational onent on a shelf, or is lims. It becomes insteadional workshops and buzz or is limited to some aimed to a practically useful toords for PR-material, choices make the core values al. In this project we throughout the Thus remaining checklist to measure customer happinocess. Instead of measuring relevant

\section{DENTIFYING A WEB OF VALUES}

in To identify values in public sectiss issioners. Often they The municipalities might be foundation or other project in turn get funding from a foundation values they expect funder, who in turn have by-laws and. At the same time in to be filled by the projects they fund. At is in the bigger a democratic society the municipality shared by the picture run by the public and the value and have different pitizens, who of course also don 't agree aning web of values political ideas. This creates an intertwining we of and final political design choices, design process and final design.

More abstract long-term project goals such as democratic More abstact long- development goals and similar can values, sustract that they are not used in the day to day become so abstract that in the design process. It becomes work, thus getting lost in the do some a value document on a shorial, inspirational workshops and buzz In this project the core inspirad of a practically useful tool. In this project thoices instead of a prad became a checklist to measure choughout values instead becaining active and relevant throughout against. Thus remaining active towards for instance the process. Instead of measurility societal values were customer happiness and sellability, societal values were

in focus.
Throughout an iterative design process, implemented in updated, tweaked and polishoups understanding of the groups accordance with the desured against, and Similarly, the design choices wes. By treating both instand adapted to the values at fluid and possible to understand both and values as somewh the opportunity to undentified values and develop, it gave the This way the identerstanding design and values bette the more practical unentation. naturally connected to the ned for the implementation.

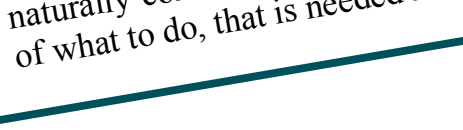

\section{In thisTAL VALUES IN THE SANDBOX \\ and the me focused on a public play}

include, municipality's values relic playground setting inclusion, are not limited to access to the accessibility, both in locagogical values, e.g. as a place for Public playgrounds fill mon as well as palace for relaxatioarning, a place for purtiple roles, their parents. 


\section{IMPLEMENTING SOCIETAL VALUES}

Societal values were identified from project goals, application, stakeholders aims etc. and participatory design permeates the whole process. Children were involved in an inventory of needs study, where 20 children workshopped and made collaborative drawings of playgrounds. This was complemented with studying the children at a playground to map their behavior to their orally expressed needs, as these might differ. As an example, in the drawings several voiced the need for long funnel slides. However, when actually playing most children instead choose to play all together at a shorter, broad slide where they could interact and slide together. Further, the municipality had a civic dialogue where citizens, especially nearby residents, contributed with feedback on the playground plans, and during design iterations, children were involved in testing prototypes, being observed playing, as well as interviewed about the experience and given a chance to share their ideas.

After inaugurations, user studies have be conducted in the final playground. As a result of this, the reprogrammable parts of the playground have kept evolving. See later pages for more details on these studies

"TRIPLE HELIX" CONSORTIUM The project used a "triple helix" consortium with the me project, we partaking organisations had inters in the design work.

consider them all as stakeholders in the design work

- 2 Universities: Design and action research oriented researcher involved in design and studies.

- 2 Companies: Tech and sustaking municipally is a medium sized swedish town. Of playground - 1 Municipally: The partaking municipally including the department of urban planning, including

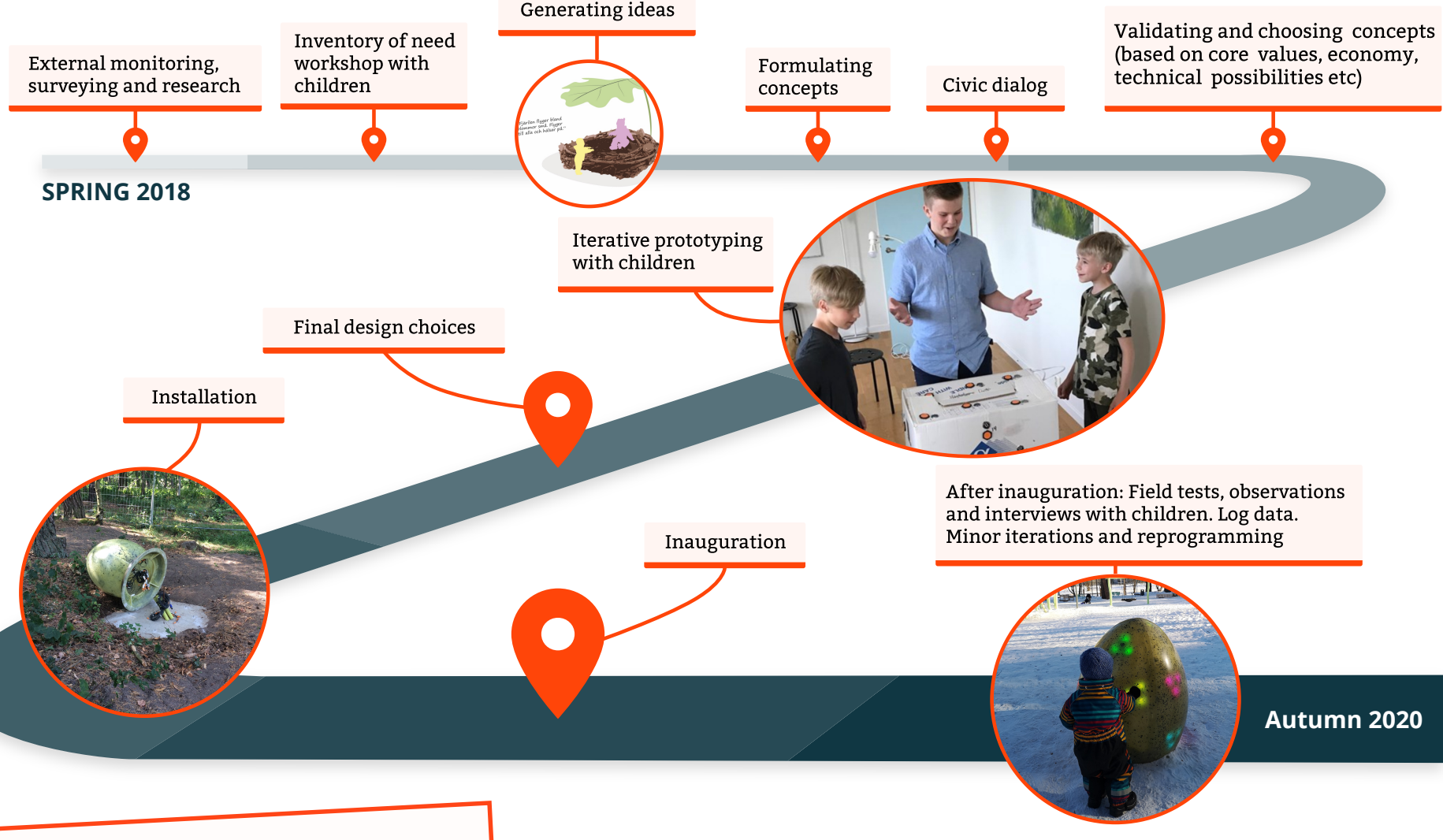

Government Funding/application

- Innovation connected to internet of things

- Democracy

- The Global Goals

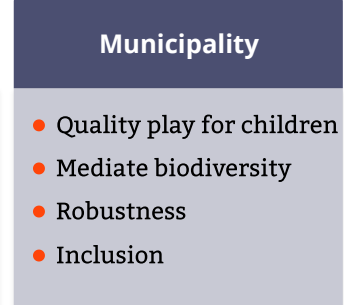

Researchers

Play values and diversified play - Interpersonal perspective

Appropriation 


\section{IDENTIFYING AND USING CORE VALUES}

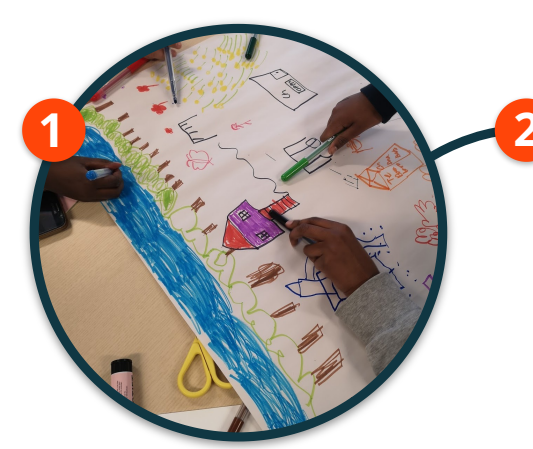

Workshops, documentation and observations to identify core values.

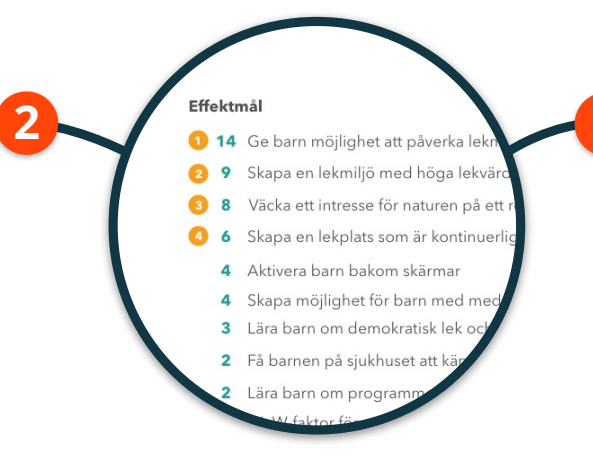

Setting up the list of Core values (14 values identified)

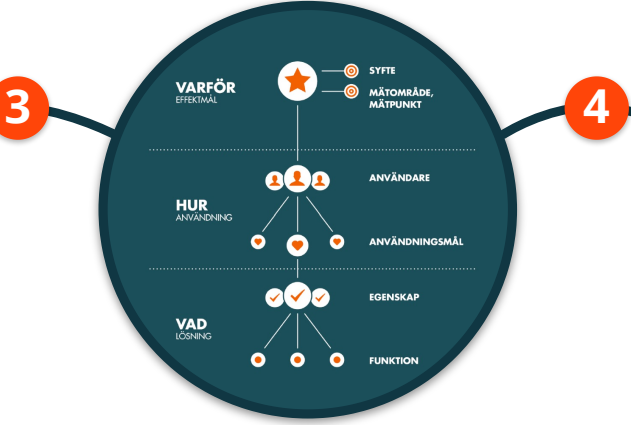

Defining the why, how and what. Clustering the Core values into a hierarchy of aggregated, underlying values and more direct values.

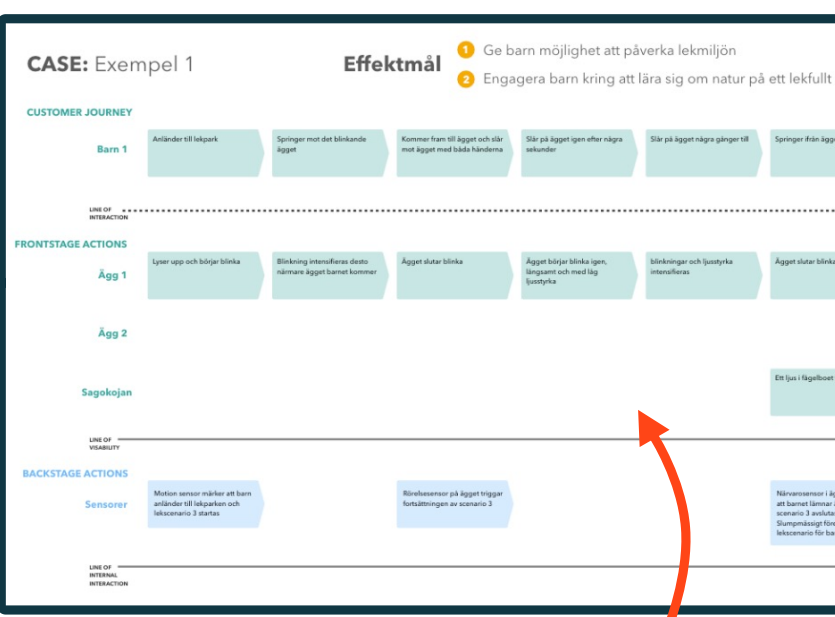

Service blueprint and actual tool to implement the values.

Here the Effect goals 1 and 2 are shown. They are mapped in a
Core values were identified in two major ways. First, through workshops designated to find and define core values (1). Secondly, by researchers participating in regular meetings and in conversations identify values mentioned, and lifting them in the group. For instance the municipality representative often mentioned accessibility, thus this was identified as an important value and added to the core values.

After an inventory of needs had been conducted and important values had been identified, a workshop was held with all project partners. During the workshop core values were listed and a hierarchy developed with aggregated, underlying and direct values. The values were sorted and numbered, and then turned into effect goals (2). After the workshop the effect goals were structured by how they related to use, and what would be needed to implementing them into design (3), this was explicated through service blueprints (4) that became the actual tool for implementing the values into the design.

The tool alone is not enough to ensure that the values are integrated in the design. The tool was complemented with a board of experts partaking in all major design choices, meeting at least once per week. A representative from the municipality, a play researcher, a sustainability educator and tech experts all gave their input on choices, to ensure that values were sustained throughout the design process. The values were treated as a living document. Both solutions and values undertook several iterations, with values affecting design as well as new reflections from the design affecting the values. Values sometimes conflicted with each other, and here the group discussed to find good compromises or new solutions. For instance discussing a certain solution might highlight new priorities, that when investigated resulted in identifying the need to incorporate a new core value into the design process.

6 main categories of core values were identified. Each category contained sub-values, in total 17 such values. All the values and how they are integrated into the design solutions are presented on the following pages.

\section{PLA \\ PLAY}

CHANGEABILITY FOR APPROPRIATION
APPROPRIATION

customer journey with interactions (e.g. [25]). The customer journey is mapped against frontstage actions needed to be catered for by the installations and backstage actions, not visible to users but needed for the technical implementation.

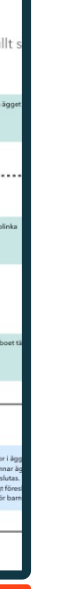

or

\author{
or
}

\author{
GAI \\ VARIATION OF PLAY \\ C
}




\section{THE INSTALLATIONS}

FACTS ABOUT THE INSTALLTIONS AND THEIR PLACEMENT

Interacting with the installations

There are in total three interactive installations: one hut the size of a playhouse and with a look inspired by birdhouses, and two big eggs, painted like wild bird eggs. The installations are placed in the outskirts of a traditional playground, between the playground and a neighbouring small forest, with about 5-10 meters in between them. The placement is intended to work as a link between playground and forest, encouraging play also in the forest. The playground and the interactive exhibits were developed in conjunction and share the local nature perspective in its execution.

When not in use the interactive installations pulsate in different coloured lights. When touching one of the sensors on the eggs or in the Hut, a name of a play scenario is spoken out

loud and that scenario starts. The scenarios are colour coded, for instance 'the blue scenario', so that children can easily choose scenarios without having to understand any written instructions.

Depending on the scenario, they play on the scenario they were started on, or they play on several installations at once, currently on the two eggs, and this way encourage users to move between them. Even though not currently activated, scenarios could also connect for instance the hut and an egg, or even installations that could be placed in other playgrounds.

Scenarios can be changed and new scenarios added, via a graphical programming interface built on Blockly [5] and accessed through a web browser. After inauguration several tweaks of existing scenarios have been made, as well as adding new scenarios. There are currently seven scenarios running. Three in the hut, and four on the eggs. Here we present some examples.

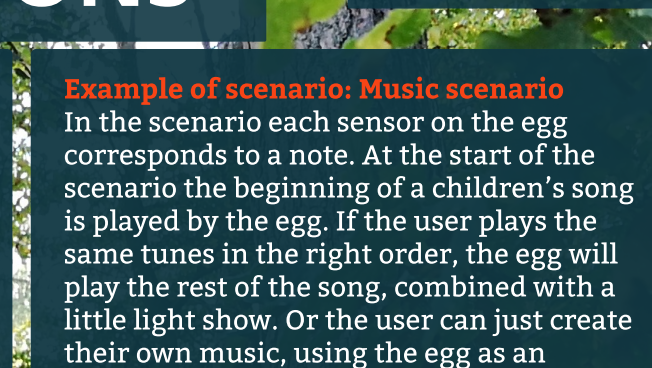

their own music, using the egg as an

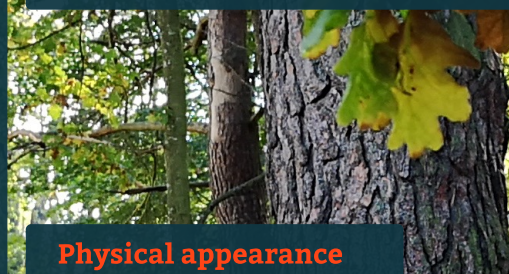

- Mimics nature

- Robust materials

मै.

Placer

- In a forest glade

- Park with meadow and trees

near urban environment

- Near a new built municipal

playground, biodiversity themed

5. Technology enhanced

- Internet of things, connected

to the cloud

- Capacative sensors

- RGB LED-lights

- Loudspeakers

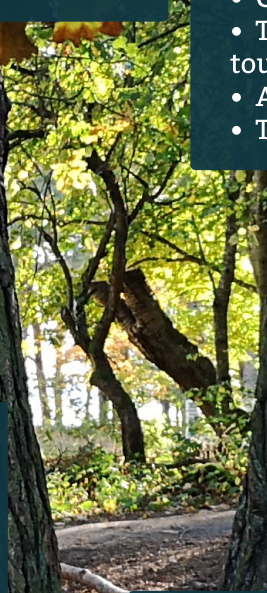
The hut also contains loudspeakers

$\begin{array}{ll}25 & \begin{array}{l}\text { interaction is interpreted and turned into a game } \\ \text { is up to the users. For instance users can choose } \\ \text { one colour each and compete in first turning } \\ \text { both eggs into the chosen colour, or users can } \\ \text { collaborate to make both eggs rainbow colored. }\end{array}\end{array}$

art?

The Egg

- 1.2 meter high

- 16 locations that can light up in any color

- Each location contains a touch sensor

- Each egg contains a loudspeaker

xample of scenario: Paint the egg

During the scenario, touching the sensors makes them change colours. The other egg mimics the interaction and also changes colour. How this

interaction is interpreted and turned into a game is up to the users. For instance users can choose one colour each and compete in first turning both eggs into the chosen colour, or users can collaborate to make both eggs rainbow colored. activating sensors, the user can decide what happens in the stories. The stories available change depending on date and time of year so The hut

tike a birdhouse

.

- Above each stool there's a spotlight that can light up in any color.
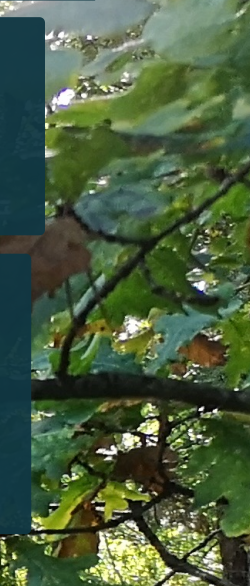

W
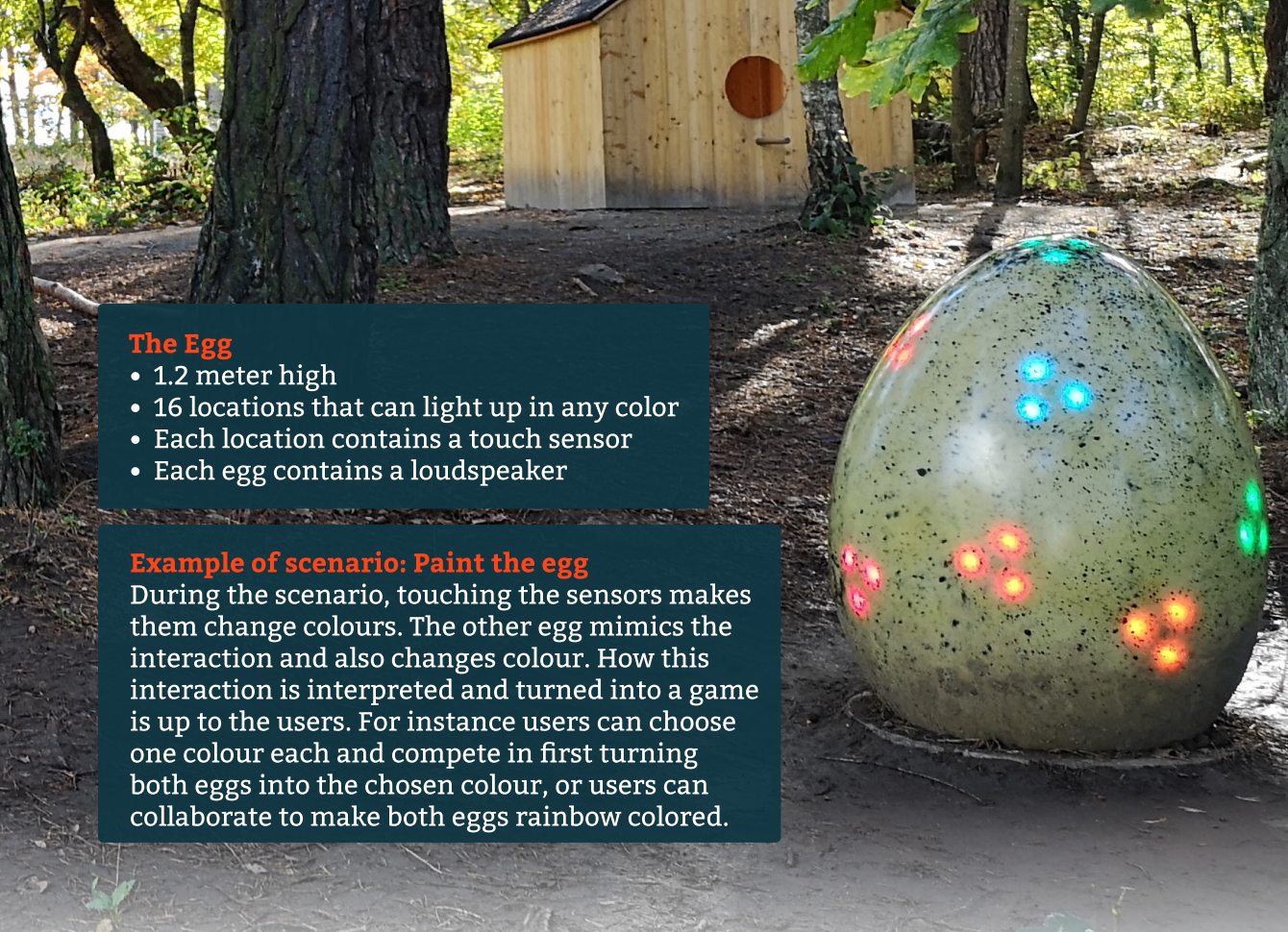


\section{APPROPRIATION}

OINTERACTIVITY

3

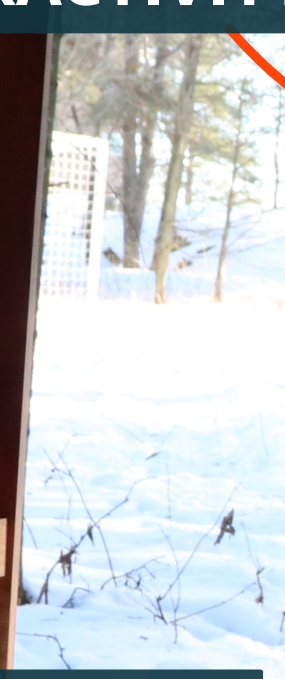

D Open end scenarios, free to interpret

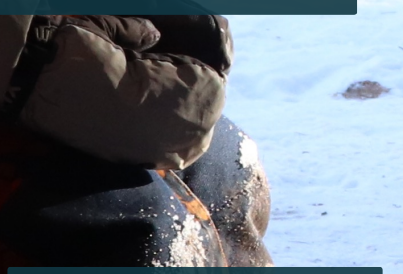

Different scenarios an
types of interactions

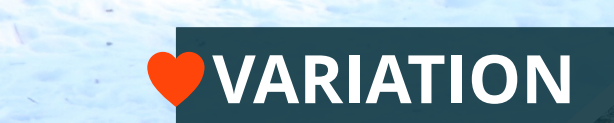

A fundamental value for well being is autonomy and competence [7]. To be empowered and feel that one can change and affect ones surroundings. Also change offers variations and the possibility to appropriate a space or an interaction [4]. But many playgrounds today are the opposite: they are static and moulded in place [3]. By designing for changeability and appropriation it is possible to cater for

democratic play [8].
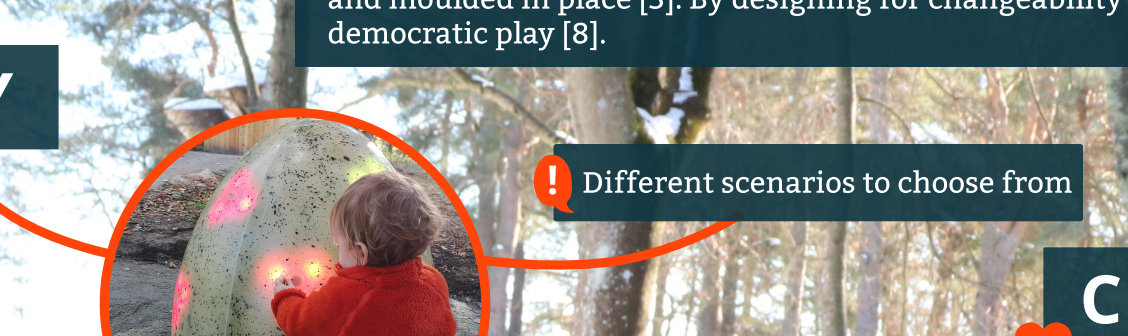

1 and

.

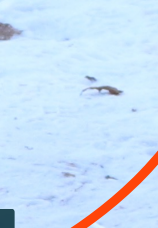

Possible to make choices while playing scenario

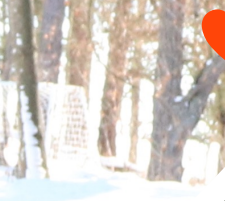

\section{CHANGEABILITY}

FOR APPROPPRIATION
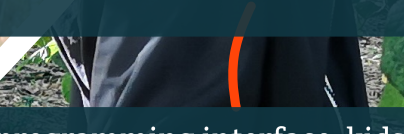

ding

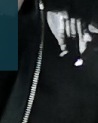

6) 


\section{PLAYIFICATION \& GAMIFICATION}

Play is fundamental to all human activity [14]. Gamification with fast rewards leads to interaction patterns such as competitiveness and addiction [1]. But there is a strength in how gamification creates flow [1]. Playification instead focuses on collaboration, discovery and playfulness [20], but still keeps the flow from gamification. Meaningful playification means including many different play typologies [19], to offer variation of play, not only play types encouraged via gamification. (2) 7. 25 a. 2 ?

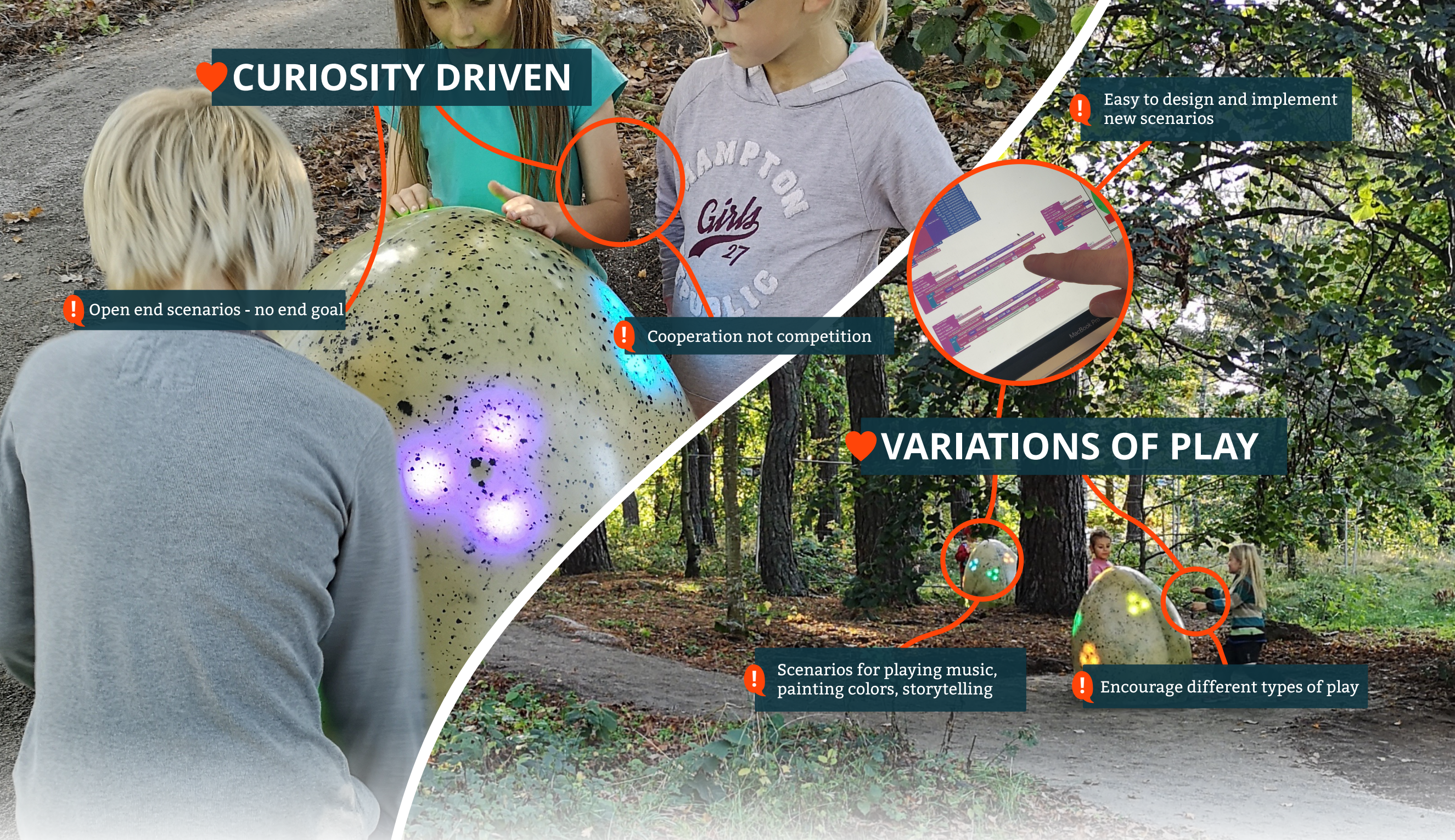


$30 x+4$

\section{ENVIRONMENT \& EMBODIMENT}

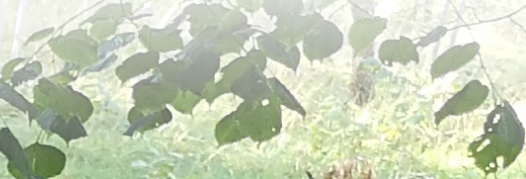

Traditional screen-based tech tends to ignore the body. With embodied interaction focus is on how our bodies relate to our experiences [9]. Technology can be used to enhance our outdoor experiences [21]. A playground is not only the installations but also the play paths created between them [3]. Integrating nature in the playscape has many positive effects on children's development and helps them create an environmental identity [22].

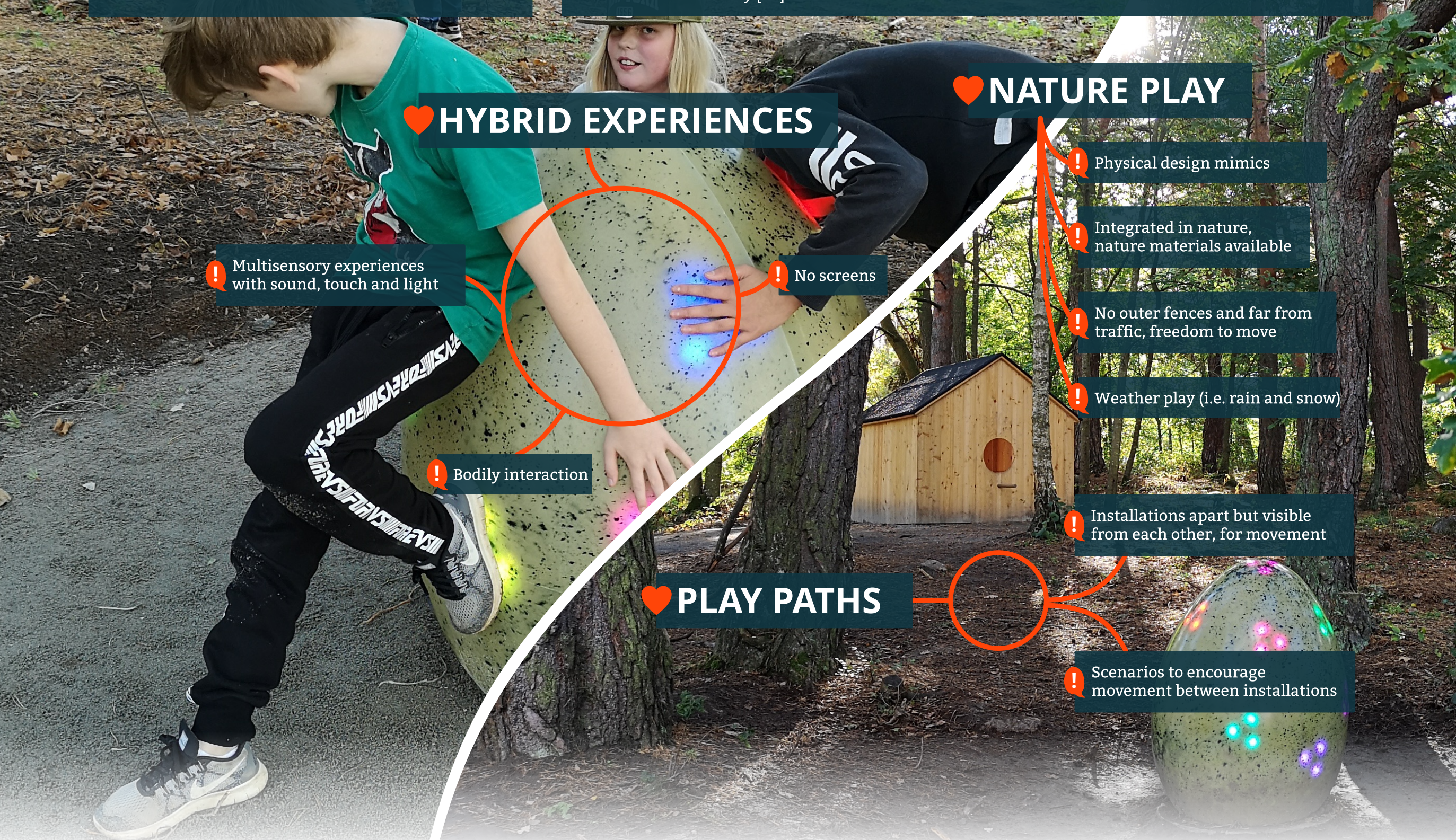




\section{LEARNING}

EXPERIENCES

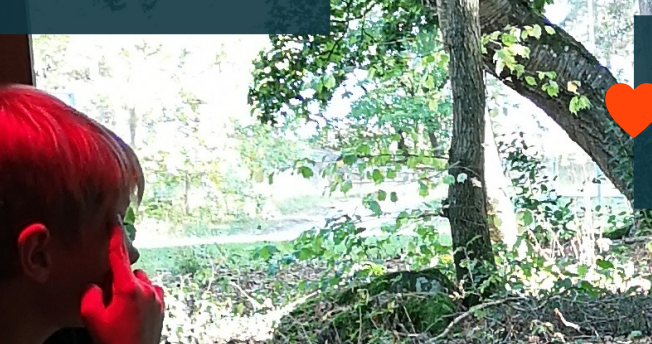

All play is learning and you can learn through play [8, 14]. Emotional engagement [26], storytelling [2] and experiences [18] are powerful ways of creating playful learning. Especially interactive storytelling can create positive effects on learning, and here mixed reality technology can play a role [6].

STORIES ARE INTERACTIVE AND CHANGES

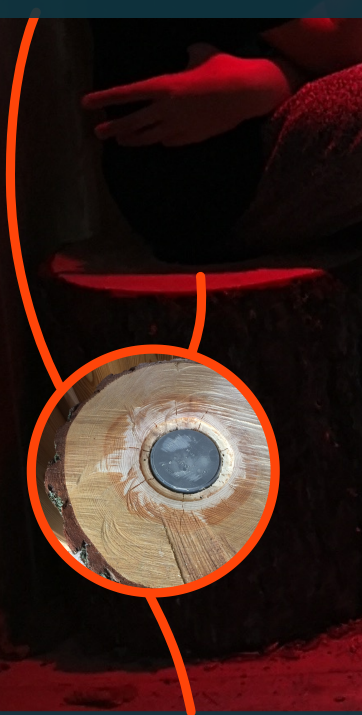

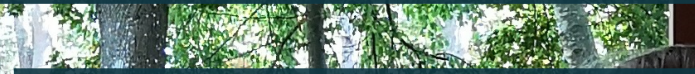

DESIGNED FOR SITTING AND LISTENING

-
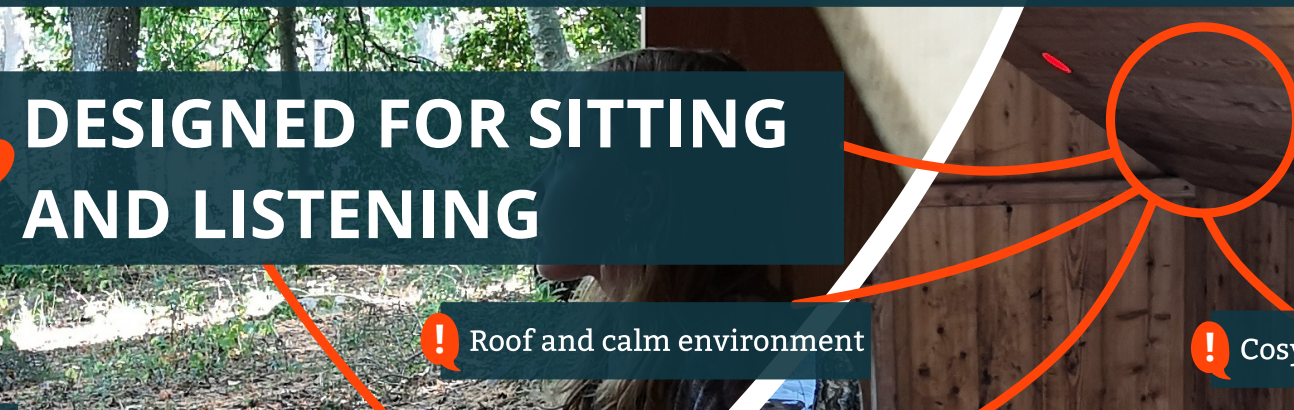

Cosy lights

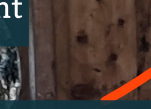

! Lights and loudspeakers above the seats
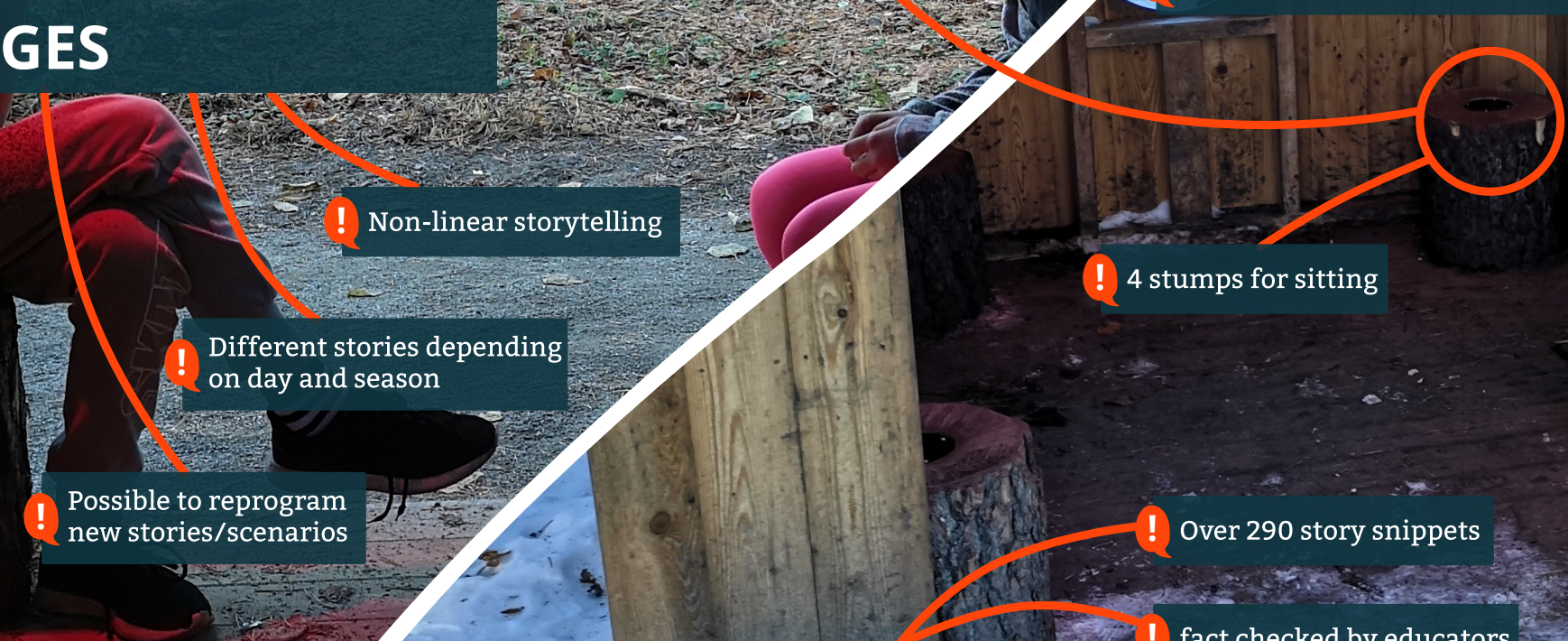

! 4 stumps for sitting

Capacitive sensors for making choices in the stories

\section{STORIES ABOUT NATURE}
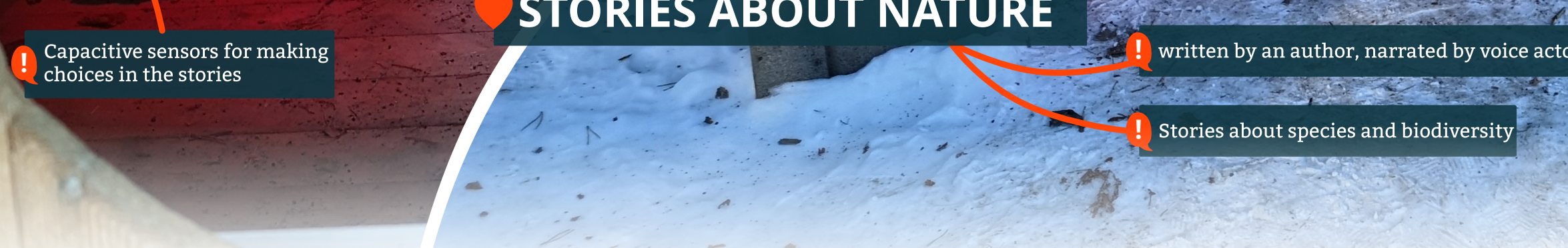


\section{RESULTS AND TESTS AFTER INAUGURATION}

After the inauguration of the playground, several studies have been performed. At three different occasions, in the fall, winter, and spring, researchers have visited the playground for observations and interviews with users of the playground. After presenting themselves and asking for consent, the researchers took a step back to observe. Afterwards, interviews were conducted with both parents and children, focusing on their experience of the playground as well as tying into observed play behaviour. The observation data was complemented with data logs from the installations, to get a broader understanding of when and how often the equipment was used. The resulting data has been coded, with project values in mind, to evaluate values and effect goals. This is still an ongoing work, and further observations and analysis is planned. In particular, one more session in summer weather will be performed, to thereby cover all seasons. More detailed descriptions of this will be published in forthcoming papers.

The playground is ever-changing, and parallel to the observations, designerly knowledge has been gathered through workshops and design tasks in early school years, as well as through course work at university level. While children needed support and a grown up to help them with programming, they were still able to make pen-and-paper sketches and designs that could be implemented in the playground. The university students were able to implement scenarios that could be taken into the design, and among the currently running scenarios, one is developed by this group. An ongoing work, that we hope to explore further is to find a sustainable way to open up the programming more widely to a broader, and younger audience. Together with the municipally we are working towards classroom education and children's holiday workshops where they could develop, and implement new scenarios for use by all visitors to the playground.

\section{Reprogrammed several times}

- The team made an advent calendar scenario for christmas

- Students made a music scenario that was implemented

- New sounds and scenarios added on several occasions, based on feedback

\section{User data}

- Total 1588 initiated scenario interactions over 2 weeks in February. Data gained by logging triggering of sensors activating scenarios.

- Installations have been active and working 24/7 since inauguration

- Endured -15 temperature, rain, snow, $1 \mathrm{dm}$ of water around the base and one attempted vandalism with screwdrivers
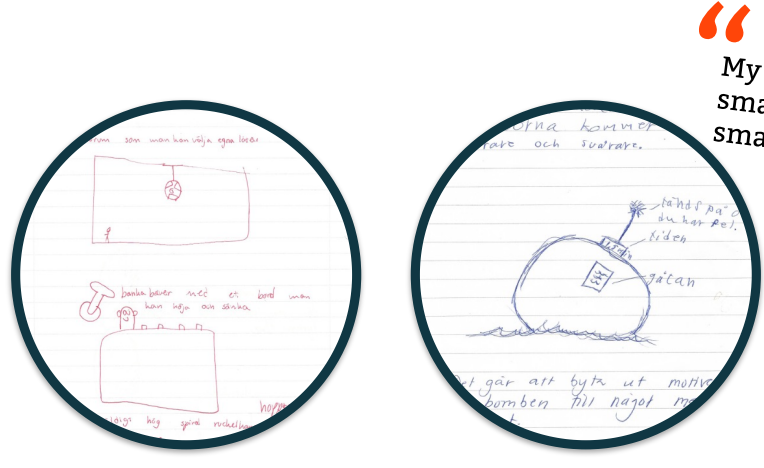

Examples of scenarios and playground designs by 12 years old - after excursion to the

playground and learning the programming tool

\section{0}

the play interactions [meaning the tech

installations] outdoors are cool and my daughter very much likes especially the stories [...] we have never seen anything like this - Father of a girl (age 3)

small, riding on a bumded she was super

small wooden hut with sto bee, flying to a

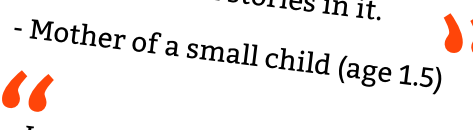
I can play music on the egg - Boy (age 5)

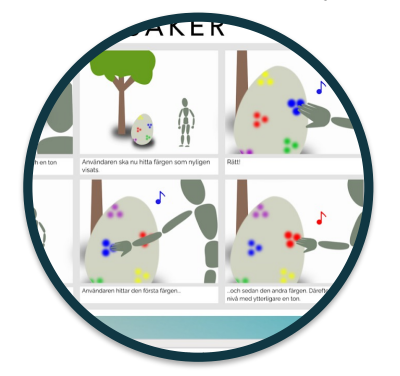

Detail from storyboard. Scenario design by local university students

\section{CONCLUSION}

In this pictorial, we present how societal values can be concretely manifested and incorporated in an actual design when it comes to designing playground installations. Using a design research-oriented approach in direct collaboration with industry partners and a municipality, we gathered knowledge throughout the design of an outdoor playground meant for everyday 'real' use. Presenting this through annotated portfolio-inspired illustrations of the installation, we show how these societal values affected the design.

Even though the identified 'webb of values' may not always be as easy to define and structure as it may seem from the presentation of this case, we still argue for the importance of having societal values in mind as a design tool, especially in public settings. Values are all interrelated, and may sometimes even be in opposition to each other. By adapting and trying to understand both values, and the design, throughout an iterative design process, we found a way to identify and balance these values against both each other and the design. However, it is important to note that this is one case, and not intended to be a single solution for all situations. It is rather intended as one inspirational case, that might be useful for others designing in public settings. Although not the primary focus of this pictorial, our preliminary tests and studies show that the playground installations are frequently used, well working, and that they enhance play experience and cater for many different types of play. Pointing towards a positive reception of the design from the local public.

\section{ACKNOWLEDGMENTS}

The project Play IT (DNR 2018-01511) is a part of the Strategical Innovation Program IoT Sweden, with funding from Vinnova, Formas and Energimyndigheten. 


\section{REFERENCES}

1. Fernando R. H. Andrade, Riichiro Mizoguchi, and Seiji Isotani. 2016. The Bright and Dark Sides of Gamification. Intelligent Tutoring Systems, Springer International Publishing, 176-186.

2. Berke Atasoy and Jean-Bernard Martens. 2011. Crafting user experiences by incorporating dramaturgical techniques of storytelling. Procedings of the Second Conference on Creativity and Innovation in Design, Association for Computing Machinery, 91-102.

3. Jon Back, Caspar Heeffer, Susan Paget, Andreas Rau, Eva Lotta Sallnäs Pysander, and Annika Waern. 2016. Designing for Children's Outdoor Play. Proceedings of the 2016 ACM Conference on Designing Interactive Systems, 28-38.

4. Jon Back, Elena Marquez Segura, and Annika Waern. 2017. Designing for Transformative Play. AC Transactions of Computer-Human Interactions 24, 3: 18:1-18:28.

5. Fred Charles, Marc Cavazza, Steven J. Mead, Olivier Martin, Alok Nandi, and Xavier Marichal. 2004. Compelling experiences in mixed reality interactive storytelling. Proceedings of the 2004 ACM SIGCHI International Conference on Advances in computer entertainment technology, Association for Computing Machinery, 32-40.

6. Edward L. Deci and Richard M. Ryan. 2013. Intrinsic Motivation and Self-Determination in Human Behavior. Springer Science \& Business Media.

7. John Dewey. 2013. Democracy and Education. Read Books Ltd.
8. Paul Dourish. 2004. Where the Action is: The Foundations of Embodied Interaction. MIT Press.

9. Lina Eklund. 2020. A Shoe Is a Shoe Is a Shoe: Interpersonalization and Meaning-making in Museums - Research Findings and Design Implications. International Journal of HumanComputer Interaction 36, 16: 1503-1513.

10. Mary Flanagan, Daniel C. Howe, and Helen Nissenbaum. 2008. Embodying values in technology: Theory and practice. Information technology and moral philosophy 322.

11. Batya Friedman and David G. Hendry. 2019. Value Sensitive Design: Shaping Technology with Moral Imagination. MIT Press.

12. Batya Friedman, Peter H Kahn, and Alan Borning. 2002. Value Sensitive Design: Theory and Methods. Dept. Of Computer Science \& Engineering University of Washington, Technical Report, Washington.

13. John L. Gillin and J. Huizinga. 1951. Homo Ludens: A Study of the Play-Element in Culture. American Sociological Review 16, 2: 274.

14. K. R. Ginsburg, and the Committee on Communications, and the Committee on Psychosocial Aspects of Child and Family Health. 2007. The Importance of Play in Promoting Healthy Child Development and Maintaining Strong ParentChild Bonds. PEDIATRICS 119, 1: 182-191.

15. Erving Goffman. 1959. The Presentation of Self in Everyday Life. Doubleday.

16. David G. Hendry, Batya Friedman, and Stephanie Ballard. 2021. Value sensitive design as a formative framework. Ethics and Information Technology.
17. David A. Kolb. 2014. Experiential Learning: Experience as the Source of Learning and Development. FT Press.

18. Janet Loebach and Adina Cox. 2020. Tool for Observing Play Outdoors (TOPO): A New Typology for Capturing Children's Play Behaviors in Outdoor Environments. International Journal of Environmental Research and Public Health 17: 5611 .

19. Elena Márquez Segura, Annika Waern, Luis Segura, and David Recio. 2016. Playification: The PhySeEar case.

20. Ashley Parsons. 2011. Young Children and Nature: Outdoor Play and Development, Experiences Fostering Environmental Consciousness, And the Implications on Playground Design. Retrieved February 11, 2021 from https://vtechworks.lib.vt.edu/handle/10919/32281.

21. Donald A Schön. 1983. The reflective practitioner: how professionals think in action. Basic Books, New York.

22. Tina L. Stanton-Chapman and Eric L. Schmidt. 2017. Creating an Inclusive Playground for Children of All Abilities: West Fork Playground in Cincinnati, Ohio. Children, Youth and Environments 27, 3: 124-137.

23. Marc Stickdorn, Markus Hormess, Adam Lawrence, and Jakob Schneider, eds. 2018. This is service design doing: applying service design thinking in the real world; a practitioners handbook. O'Reilly, Sebastapol, CA.

24. Chai M. Tyng, Hafeez U. Amin, Mohamad N. M. Saad, and Aamir S. Malik. 2017. The Influences of 
Emotion on Learning and Memory. Frontiers in Psychology 8 .

25. Blockly. Google Developers. Retrieved April 28, 2021 from https://developers.google.com/blockly.
26. NatureCollections: Can a Mobile Application Trigger Children's Interest in Nature? - CSEDU 2020. Retrieved January 18, 2021 from https://www.insticc.org/node/TechnicalProgram/cse $\mathrm{du} / 2020 /$ presentationDetails/94211. 